\title{
CONF- $970834=$
}

\section{BEAM-BROADENING EFFECTS IN STEM/EDS MEASUREMENT OF RADIATION-INDUCED SEGREGATION IN HIGH-PURITY 304L STAINLESS STEEL*}

\author{
J. T. Busby 1 , T. R. Allen 1,2 , E. A. Kenik ${ }^{3}$, N. J. Zaluzec ${ }^{4}$, and G. S. Was ${ }^{1}$ \\ 1University of Michigan \\ Dept. of Nuclear Engineering and Radiological Sciences \\ Ann Arbor, MI 48109 \\ 2 Argonne National Laboratory-West \\ Idaho Falls, ID 83403 \\ 3 Metals and Ceramics Division \\ Oak Ridge National Laboratory \\ Oak Ridge, TN 37831 \\ 4Materials Science Division \\ Argonne National Laboratory \\ 9700 S. Cass Ave. \\ Argonne, IL 60439 \\ $\sin 20$ \\ Hoy 98997 \\ 031 \\ October 1997

The submited manuscript has been created by the
University of Chicago as Operator of Argonne National
Laboratory ("Argonne") under Contract No. W-31-109-ENG-
38 with the U.S. Department of Energy. The U.S.
Government retains for itself, and others acting on its
behalf, a paid-up, non exclusive, irrevocable worldwide
license in said article to reproduce, prepare derivative
works, distribute copies to the public, and perform
publicly and display publicly, by or on behalf of the
Government. \\ Government
}

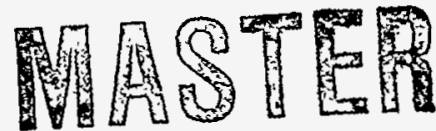

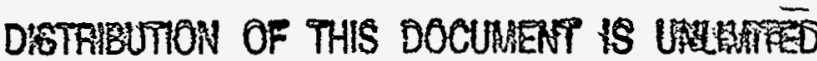

To be submitted to Microscopy and Microanalysis, Cleveland, OH, August 10-14, 1997.

*This research was supported by the U.S. Department of Energy under grant DE-FG02-93ER-123T0, by the Associated Western Universities-Northwest under U.S. Department of Energy grant DE-FG02-89ER7552. Research partially supported by the Division of Materials Sciences, U.S. Department of Energy under contract DE-AC05-960R22464 with Lockheed Martin Energy Research Corp., through the SHARE Program under contract DE-AC05-760R000333with ORAU. 


\section{DISCLAIMER}

This report was prepared as an account of work sponsored by an agency of the United States Government. Neither the United States Government nor any agency thereof, nor any of their employees, makes any warranty, express or implied, or assumes any legal liability or responsibility for the accuracy, completeness, or use. fulness of any information, apparatus, product, or process disclosed, or represents that its use would not infringe privately owned rights. Reference herein to any specific commercial product, process, or service by trade name, trademark, manufacturer, or otherwise does not necessarily constitute or imply its endorsement, recommendation, or favoring by the United States Government or any agency thereof. The views and opinions of authors expressed herein do not necessarily state or reflect those of the United States Government or any agency thereof. 


\section{DISCLAIMER}

Portions of this document may be Illegible in electronic image products. Images are produced from the best available original document 
BEAM-BROADENING EFFECTS IN STEM/EDS MEASUREMENT OF RADIATIONINDUCED SEGREGATION IN HIGH-PURTTY 304L STAINLESS STEEL

\author{
J.T. Busby', T.R. Allen ${ }^{1,2}$, E.A. Kenik ${ }^{3}$, N.J. Zaluzec ${ }^{4}$, G.S. Was ${ }^{1}$ \\ 'The University of Michigan, Dept. of Nuclear Engineering and Radiological Sciences \\ Ann Arbor, MI 48109. \\ ${ }^{2}$ Argonne National Laboratory-West, Idaho Falls, ID 83403 \\ ${ }^{3}$ Metals and Ceramics Division, Oak Ridge National Laboratory, Oak Ridge, TN 37831 \\ ${ }^{4}$ Metals and Ceramics Division, Argonne National Laboratory, Argonne, IL 60439
}

Radiation-induced segregation (RIS) is the spatial redistribution of elements at defect sinks such as grain boundaries and free surfaces during irradiation. This phenomenon has been studied in a wide variety of alloys and has been linked to irradiation-assisted stress corrosion cracking (IASCC) of nuclear reactor core components'. Therefore, accurate determination of the grain boundary composition is important in understanding its effects on environmental cracking. Radiation-induced segregation profiles are routinely measured by scanning-transmission electron microscopy using energy-dispersive X-ray spectroscopy (STEM-EDS) and Auger electron spectroscopy (AES). Because of the narrow width of the segregation profile (typically less than $10-\mathrm{nm}$ full width at half-maximum), the accuracy of grain boundary concentration measurements using STEM/EDS depends on the characteristics of the analyzing instrument, specifically, the excited volume in which $x$-rays are generated. This excited volume is determined by both electron beam diameter and the primary electron beam energy. Increasing the primary beam energy in STEM/EDS produces greater measured grain boundary segregation, as the reduced electron beam broadening a smaller excited volume. In this work, the effect of beam broadening is assessed on segregation measurements in a 304L stainless steel sample irradiated with $3.2 \mathrm{MeV}$ protons at $400^{\circ} \mathrm{C}$ to doses of 3.0 and $0.1 \mathrm{dpa}$. The STEM/EDS measurements are also compared to measurements made using AES.

High-purity $304 \mathrm{~L}$ stainless steel samples with the nominal composition of 20.9 at $\% \mathrm{Cr}, 9.0$ at $\% \mathrm{Ni}$, and 69.0 at $\% \mathrm{Fe}$ as determined by electron microprobe analysis were used. Samples were irradiated with 3.2 $\mathrm{MeV}$ protons at a dose rate of approximately $7.0 \times 10^{-6} \mathrm{dpa} / \mathrm{s}$ to 3.0 and $0.1 \mathrm{dpa}$. The sample temperature during irradiation was maintained at $400^{\circ} \pm 10^{\circ} \mathrm{C}$. Further details of the sample preparation and irradiation are given in Ref 2.

Measurement of grain boundary composition by STEM/EDS was performed on a Philips EM400T/FEG and a Philips CM200/FEG at Oak Ridge National Laboratory. The EM400T has an incident beam size of $2 \mathrm{~nm}$ (full-width tenth maximum) and operates at $100 \mathrm{kV}$. The CM200 has an effective probe size of $2 \mathrm{~nm}$ (full-width tenth maximum) and operates at $200 \mathrm{kV}$. A double-tilt, liquid-nitrogen-cooled specimen holder was used to minimize contamination of the sample in the focused beam ${ }^{3}$. Grain boundaries were aligned parallel to the incident electron beam. Subtraction of "in-hole" spectra from the measured spectra was performed to correct for uncollimated radiation from the microscope illuminations system and radiation associated with residual radioactivity in the sample. Collected raw intensities were converted to atomic concentrations using $k$-factors ${ }^{4}$ calculated from comparison of EDS-determined matrix intensities to the bulk alloy composition determined independently by electron microprobe analysis.

The same high-dose sample in the same geometry was examined in both instruments. The same grain boundaries were analyzed in the same region of the foil. Both grain boundary measurements and segregation profiles were taken on each instrument. The results of the grain boundary $\mathrm{Cr}$ and $\mathrm{Ni}$ measurements are illustrated in Figure 1. Clearly, instrument type and beam broadening shows a significant effect on the measured segregation. As expected, the CM200 operating at $200 \mathrm{kV}$ measures more $\mathrm{Cr}$ and $\mathrm{Ni}$ segregation than the EM400T since less matrix material is excited by the higher energy incident beam. Results of AES analysis of samples from the same irradiation are also shown in Fig 1 in 
order to compare the two techniques. The AES technique measures more segregation than either instrument using STEM/EDS. Results will also be compared with measurements taken on the same sample using a $300 \mathrm{kV}$ dedicated STEM instrument and with measurements taken from the low dose sample on all instruments.

Segregation profiles were also taken for the high dose sample using both TEM instruments across the same grain boundaries. The $\mathrm{Cr}$ and $\mathrm{Ni}$ segregation profiles for one of these boundaries is shown in Fig. 2 . The profile measured by the CM200 is deeper and more narrow than that measured by the EM400T. Again, as less volume is excited, more segregation is measured and the amount of detail in the profile is increased. These profiles will also be compared to those measured by a $300 \mathrm{kV}$ dedicated STEM instrument.

This research was supported by the U.S. Department of Energy under grant DE-FG02-93ER-12310, by the Associated Western Universities-Northwest under U.S. Department of Energy grant DE-FG02-89ER7552. Research partially supported by the Division of Materials Sciences, U.S. Department of Energy under contract DE-AC05-960R22464 with Lockheed Martin Energy Research Corp., through the SHaRE Program under contract DE-AC05-760R000333 with ORAU.

\section{References}

1. G.S. Was and P. Andresen, J.Metals 44 (4) (1992) 8.

2. D.L. Damcott, J.M. Cookson, R.D. Carter, Jr., J.R. Martin, M. Atzmon, and G.S. Was, Radiat. Eff. Def. Solids, 118 (1991) 383.

3. E.A. Kenik, Scripta Metall. 21 (1987) 811.

4. J.I. Goldstein, in Principles of Analytical Microscopy, eds. D.C. Joy, A.D. Romig and J.I. Goldstein (Plenum, New York, 1986).

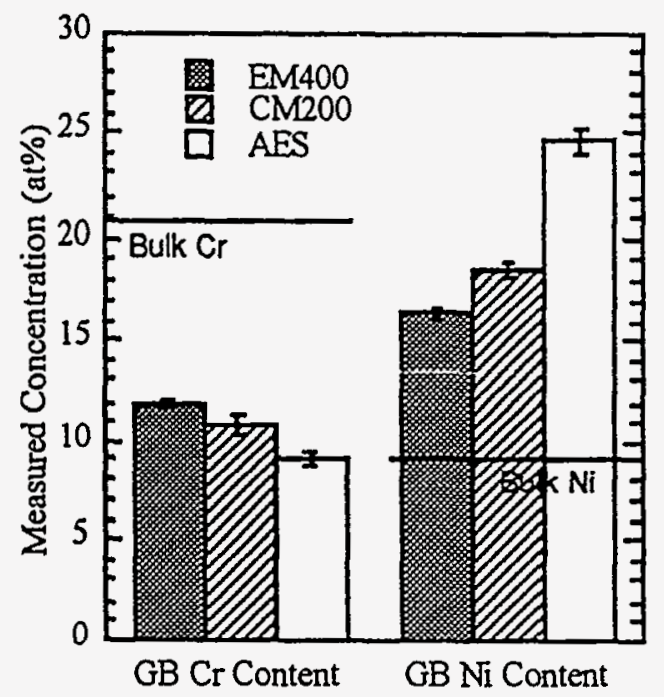

Fig. 1: A comparison of the $\mathrm{GB} \mathrm{Cr}$ and $\mathrm{Ni}$ composition measurement for 304L SS irradiated to $3.0 \mathrm{dpa}$ at $400^{\circ} \mathrm{C}$ with 3.2 $\mathrm{MeV}$ protons. Error bars represent the standard deviation of the mean.

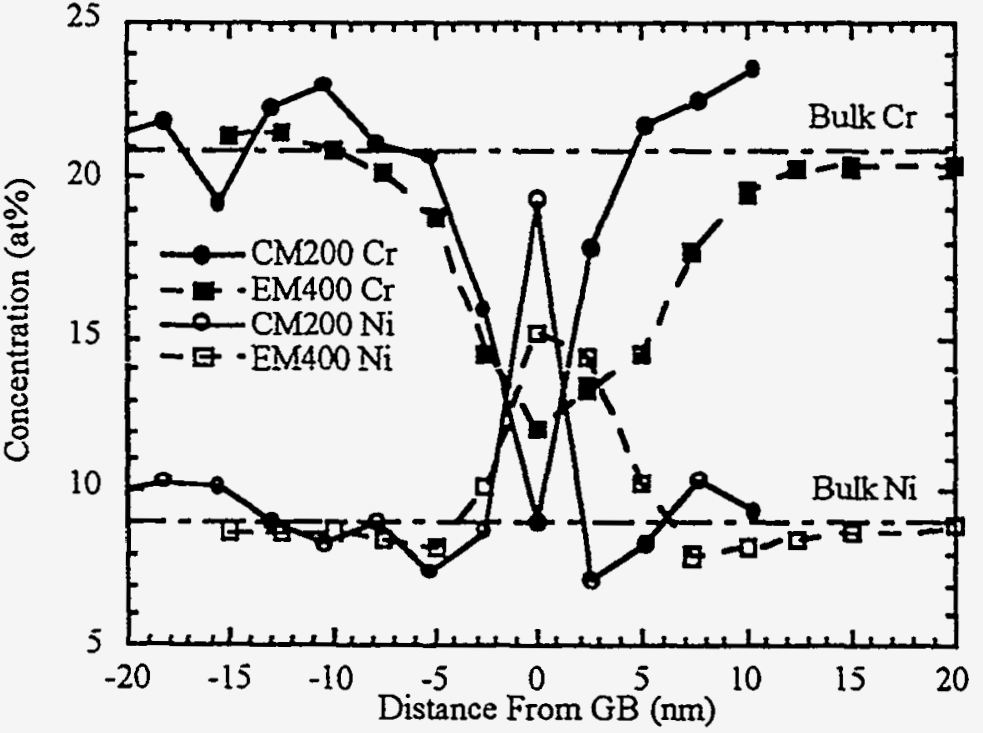

Fig. 2: A comparison of the $\mathrm{GB} \mathrm{Cr}$ and $\mathrm{Ni}$ profiles for 304L SS irradiated to $3.0 \mathrm{dpa}$ at $400^{\circ} \mathrm{C}$ with $3.2 \mathrm{MeV}$ protons for the EM400T and CM200. 